Article

\title{
Stormwater Biofilters as Barriers against Campylobacter jejuni, Cryptosporidium Oocysts and Adenoviruses; Results from a Laboratory Trial
}

\author{
Gayani Chandrasena ${ }^{1,2}$, Ana Deletic ${ }^{1,2,3}$, Anna Lintern ${ }^{4}$, Rebekah Henry ${ }^{1,2}$ and \\ David McCarthy ${ }^{1,2, *}$ \\ 1 Environmental and Public Health Microbiology Laboratory (EPHM Lab), Monash Water for Liveability, \\ Department of Civil Engineering, Monash University, Wellington Road, Clayton, Victoria 3800, Australia; \\ gayani.chandrasena@gmail.com (G.C.); a.deletic@unsw.edu.au (A.D.); Rebekah.Henry@monash.edu (R.H.) \\ Cooperative Research Centre for Water Sensitive Cities, Melbourne, Victoria 3800, Australia \\ School of Civil and Environmental Engineering, University of New South Wales, Sydney NSW 2052, Australia \\ 4 Department of Civil Engineering, Monash University, Wellington Road, Clayton, Victoria 3800, Australia; \\ Anna.Lintern@monash.edu \\ * Correspondence: David.McCarthy@monash.edu; Tel.: +61-3-9905-4944
}

Received: 24 September 2017; Accepted: 1 December 2017; Published: 6 December 2017

\begin{abstract}
Biofilters are a widely used stormwater treatment technology. However; other than some evidence regarding non-pathogenic indicator microorganisms; there are significant knowledge gaps in the capacity of stormwater biofilters to remove actual pathogens and how this removal is impacted by biofilter design elements and operational conditions. In this study; we explored the capacity of stormwater biofilters to remove three reference pathogens (Campylobacter spp.; adenovirus and Cryptosporidium oocysts) and compared these to commonly used indicator microorganisms (E. coli; FRNA coliphages and Clostridium perfringens). Two different biofilter designs; each having a submerged zone (SZ); were tested under extended dry weather periods (up to 4 weeks) and different event volumes (the equivalent of 1-2 pore volumes) in a laboratory trial. These systems were able to consistently reduce the concentrations of all tested reference pathogens (average log reduction in Campylobacter spp. $=0.7$; adenovirus $=1.0$ and Cryptosporidium oocysts $=1.7$ ) and two of the indicators (average log reduction in E. coli $=1.2$ and C. perfringens $=2.1$ ). However; none of the tested indicators consistently mimicked the removal performance of their corresponding reference pathogens after extended dry weather periods and during larger simulated storm events. This indicates that the behaviour of these pathogens in stormwater biofilters are not adequately represented by their corresponding indicator microorganisms and that to optimise biofilter designs for pathogen removal it is critical to further study pathogen removal processes in these systems.
\end{abstract}

Keywords: adenoviruses; Campylobacter; Cryptosporidium oocysts; rain garden; stormwater harvesting; stormwater management

\section{Introduction}

Stormwater harvesting has great potential to reduce the pressure on existing water resources while protecting receiving waters from degradation [1,2]. However, stormwater contains pathogens, which can cause human health risks when stormwater is harvested for re-use or is discharged into recreational water bodies without treatment [3]. Biofilters, also known as bioretention systems or rain gardens, are a common stormwater treatment technology. Stormwater biofilters consist of planted soil-based filter media with a high sand content, a sand transition layer and a drainage layer. These systems, which could be lined, are sometimes installed with a raised outlet to create a submerged zone (SZ). 
This SZ has been shown to improve the treatment performance of biofilters by promoting denitrification [4] and maintaining plant life and filter media consistency during extended dry weather periods [5].

Almost all of the literature on microbial removal in biofilters is limited to indicator microorganisms (e.g., [6-10]), even though it is well established that indicators and pathogens respond differently to various stresses found in the natural environment $[2,11]$. Obtaining data on the capacity of biofilters to remove other faecal microorganisms (including 'reference' pathogens, as suggested by various health organisations [3]) is crucial to validate the use of biofilters to treat water for stormwater harvesting and also to protect recreational waters that receive a stormwater discharge.

Previous work on indicator microorganism removal by stormwater biofilters has demonstrated that some biofilter design elements and operational conditions greatly influence microorganism removal mechanisms [12]. For instance, vegetation with extensive root structures was shown to improve E. coli retention in stormwater biofilters [13]. Filter media modified with either antimicrobial compounds $[14,15]$ or adsorption enhancements $[16,17]$ were found to improve faecal indicator microorganism attenuation rates. Intermittent wetting/drying operation is generally associated with poor removal performances due to decreased microbial adsorption and increased microbial desorption $[7,8,17]$. Adsorption kinetics suggest that overall removal rates of microorganisms from stormwater will vary greatly with event volume [18]. However, almost all previous laboratory studies have tested microbial removal in biofilters using a single event size (i.e., a single dosing volume), even though storm sizes vary greatly in practice. Further, it is not yet known whether the pathogens and faecal indicator microorganisms have the same attenuation processes and whether the biofilter design and operational conditions affect pathogens and faecal indicator microorganism attenuation mechanisms in the same way. As such, it must be determined whether pathogen removal can be represented by the behaviour of its indicator microorganisms, or whether specific testing of pathogen removal by stormwater biofilters is necessary.

The primary objective of this laboratory study was to understand whether stormwater biofilters are an effective barrier against three of the most commonly used reference pathogens: Campylobacter jejuni, Cryptosporidium oocysts and adenoviruses. Further, the study investigates how these removal rates are influenced by the design (presence of vegetation) and operational characteristics of these systems, such as extended dry weather periods and different sized rainfall events. Finally, this study explored the potential for commonly used faecal indicator microorganisms (E. coli, FRNA coliphages, Clostridium perfringens) can be used to represent reference pathogens.

\section{Materials and Methods}

\subsection{Experimental Configurations}

This laboratory-scale study involved six biofilter columns that were part of thirty-biofilter columns originally constructed for another parallel study [19] in a greenhouse. Details of the design of the columns can be found in [19]. Briefly, each biofilter column consisted of a $1140 \mathrm{~mm}$ tall, $240 \mathrm{~mm}$ diameter PVC column. A $280 \mathrm{~mm}$ tall clear Perspex pipe was plastic welded to the top oach column, to serve as a ponding zone [4]. All columns had $400 \mathrm{~mm}$ deep filter media. The top $100 \mathrm{~mm}$ of the filter media in each configuration was mixed with an ameliorant to support plant growth (see [20] for more information). A perforated plastic collection pipe was installed at the bottom of each column to collect the treated water. An SZ was created in all columns by conveying the treated water through a raised outflow pipe which created a $440 \mathrm{~mm}$ deep SZ below the filter media layer. The SZs consisted of a gravel drainage layer (70 $\mathrm{mm}$ deep), a coarse sand layer (70 mm deep) and a washed sand layer (300 mm deep) mixed with 5\% sugarcane mulch and 5\% pinewood chips without bark by volume. Biofilter layer depths and compositions were based on the current best practice guidelines in Australia [5]. Three biofilter columns were planted with Leptospermum continentale (small shrub) (hereinafter LC) while the remaining three columns were left 
unplanted as an un-vegetated control (hereinafter WS). L. continentale was selected for the current study as it showed good faecal microorganism removal in the authors' previous work [13].

\subsection{Dosing and Sampling}

\subsubsection{Semi-Natural Stormwater Preparation}

Semi-natural stormwater was used to dose the columns similar to previous laboratory-scale experiments [21]. This was to ensure consistency of the inflow and to avoid the logistical constraints of collecting large volumes of natural stormwater. Stormwater was prepared by mixing dechlorinated tap water with sediment collected from a local stormwater wetland inlet and sieved through a $1 \mathrm{~mm}$ sieve. This mixture was then supplemented with laboratory grade chemicals to obtain target pollutant concentrations consistent with Australian urban stormwater quality ([3,22,23]; Table 1).

Table 1. Target and measured semi-natural stormwater pollutant concentrations.

\begin{tabular}{|c|c|c|c|c|}
\hline \multirow[b]{2}{*}{ Stormwater Pollutant } & \multirow[b]{2}{*}{ Unit } & \multicolumn{2}{|c|}{ Inflow Concentration } & \multirow[b]{2}{*}{ Main Source } \\
\hline & & Target & $\begin{array}{l}\text { Measured in the Inflow } \\
\text { during This Study }{ }^{1}\end{array}$ & \\
\hline E. coli & $\mathrm{MPN} / 100 \mathrm{~mL}$ & $5.9 \times 10^{4}$ & $2.8 \times 10^{4}(4.16)$ & raw sewage \\
\hline FRNA coliphages & $\mathrm{pfu} / 100 \mathrm{~mL}$ & 5.5 & $26.7(20.83)$ & laboratory culture \\
\hline C. perfringens & orgs/100 mL & 925 & $1.4 \times 10^{3}(1.73)$ & laboratory culture \\
\hline Campylobacter spp. & MPNIU/L & 33.1 & $65(19.49)$ & laboratory culture \\
\hline Adenoviruses & MPNIU/L & 1 & $11(6.50)$ & laboratory culture \\
\hline Cryptosporidium oocysts & oocysts/L & 17.6 & $9(2.53)$ & laboratory culture \\
\hline Total suspended solids & $\mathrm{mg} / \mathrm{L}$ & 100 & $86(1.44)$ & sediment \\
\hline Total phosphorus & $\mathrm{mg} / \mathrm{L}$ & 0.35 & $0.42(1.18)$ & sediment, $\mathrm{KH}_{2} \mathrm{PO}_{4}$ \\
\hline Total nitrogen & $\mathrm{mg} / \mathrm{L}$ & 2.2 & $2.92(1.17)$ & $\begin{array}{l}\text { sediment, } \mathrm{KNO}_{3} \\
\mathrm{NH}_{4} \mathrm{Cl}, \mathrm{C}_{6} \mathrm{H}_{5} \mathrm{O}_{2} \mathrm{~N}\end{array}$ \\
\hline Cadmium & $\mathrm{mg} / \mathrm{L}$ & $4.5 \times 10^{-3}$ & $8.1 \times 10^{-3}(1.40)$ & $\mathrm{Cd}\left(\mathrm{NO}_{3}\right)_{2}$ in $\mathrm{HNO}_{3}$ \\
\hline Chromium & $\mathrm{mg} / \mathrm{L}$ & $2.5 \times 10^{-2}$ & $5.4 \times 10^{-2}(1.58)$ & $\mathrm{Cr}\left(\mathrm{NO}_{3}\right)_{3}$ \\
\hline Copper & $\mathrm{mg} / \mathrm{L}$ & $5.0 \times 10^{-2}$ & $8.0 \times 10^{-2}(1.36)$ & $\mathrm{CuSO}_{4}$ \\
\hline Lead & $\mathrm{mg} / \mathrm{L}$ & $1.4 \times 10^{-1}$ & $2.7 \times 10^{-1}(1.47)$ & $\mathrm{Pb}\left(\mathrm{NO}_{3}\right)_{2}$ \\
\hline Manganese & $\mathrm{mg} / \mathrm{L}$ & $2.3 \times 10^{-1}$ & $1.9 \times 10^{-1}(1.11)$ & $\mathrm{Mn}\left(\mathrm{NO}_{3}\right)_{2}$ \\
\hline Nickel & $\mathrm{mg} / \mathrm{L}$ & $3.1 \times 10^{-2}$ & $5.0 \times 10^{-2}(1.30)$ & $\mathrm{Ni}\left(\mathrm{NO}_{3}\right)_{2}$ \\
\hline Zinc & $\mathrm{mg} / \mathrm{L}$ & $2.5 \times 10^{-1}$ & $2.6 \times 10^{-1}(1.18)$ & $\mathrm{ZnCl}_{2}$ \\
\hline
\end{tabular}

Note: ${ }^{1}$ measured concentrations are presented as Geometric mean (Geometric standard deviation). MPN—Most

Probable Number; MPNIU: Most Probable Number of Infectious Units; pfu: plaque forming units; orgs: organisms.

Raw sewage sampled from the inlet channel at the sewage treatment plant in Pakenham, Australia, was used as the source of faecal microorganisms and was mixed into the synthetic stormwater (a 1:500 ratio of sewage: stormwater mixture by volume). Use of raw sewage allowed a better representation of the natural variability of faecal microorganism concentrations and composition in natural stormwater than using a monoculture of laboratory microbial strains to spike the semi-natural stormwater. This process of mixing semi-natural stormwater with raw sewage at a 1:500 dilution ratio resulted in $E$. coli levels which reflected natural stormwater variability (Table 1 and [3]), but undetectable levels of other fecal microorganisms of interest in this study: pathogen indicators (FRNA coliphages, C. perfringens) and reference pathogens (Campylobacter, adenovirus, Cryptosporidium oocysts). As such, laboratory cultures of other test microorganisms were added to the inflow for the purpose of the current study. Semi-natural stormwater was supplemented with the diluted laboratory-grown cultures of two indicator microorganisms (FRNA coliphages and C. perfringens) in week 14, 26, 27, 31 and 41 (Figure 1). The diluted laboratory-grown cultures of the reference pathogens (Campylobacter, adenovirus, Cryptosporidium parvum), supplied by a National Association of Testing Authorities (NATA), Australia accredited laboratory and Environmental and Public Health Microbiology laboratory in Monash University were added only in weeks 27, 31, 
and 41 (Figure 1). The authors' previous experiences indicated that the chosen approach to prepare semi-natural stormwater not only resulted in achieving typical microbial concentrations found in real stormwater, but also the majority of faecal indicator bacteria (E. coli) remain unattached or attached to very small particles $(<3-\mu \mathrm{m})$ in semi-natural stormwater similar to the natural stormwater collected from a Melbourne suburb [24].

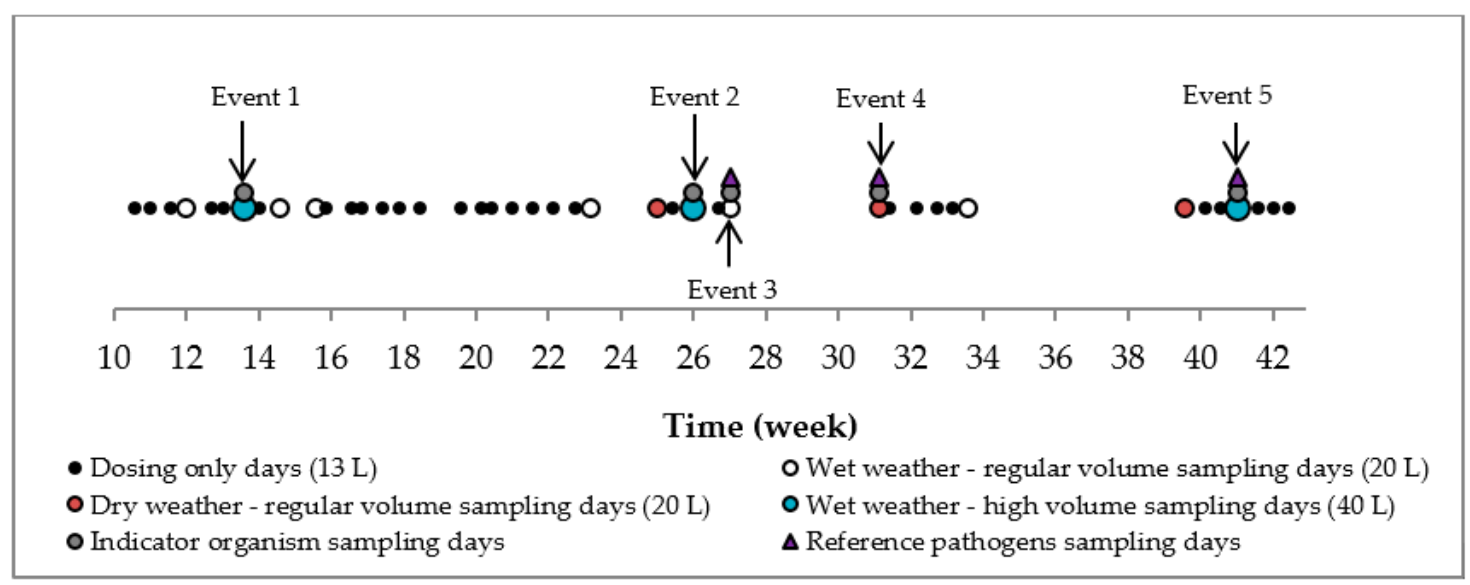

Figure 1. Dosing and sampling plan. Five indicator microorganism sampling days and three reference pathogen sampling days were within the scope of this study. Remaining sampling days were within the scope of the other parallel study [19].

\subsubsection{Dosing Frequency and Volumes}

The dosing frequency and volumes are outlined in Figure 1. Since, the current study was conducted in parallel to another study [19], the dosing frequency was designed to accommodate the scopes of both studies. Each biofilter column was dosed with $13 \mathrm{~L}$ of semi-natural stormwater twice a week (using at least three 3-5 L passes/rounds to ensure consistent inflow into all of the columns). This weekly dosing frequency and volume reflect Melbourne's historical climate patterns [21]. The $13 \mathrm{~L}$ dosing volume was estimated to be equivalent to a rainfall event of $5.75 \mathrm{~mm}$ and at the same time equal to 0.7 pore volumes (PV) of the biofilter columns. Pore volume estimated from a $\mathrm{KCl}$ tracer test conducted in un-vegetated pilot columns prior to week 10 (See Supplementary Materials for more details on tracer test).

Dosing volumes were increased on the days where the performance of the systems was evaluated (i.e., when inflow and outflow water samples were collected). The volumes used were: (1) $20 \mathrm{~L}$, which is the 1 in 1-month average recurrence interval (ARI) event and equivalent to $1 \mathrm{PV}$ (equivalent loading of $8.84 \mathrm{~mm}$ per event) or (2) $40 \mathrm{~L}$ which is equal to a 1 in 3-month ARI event and 2 PVs (equivalent loading of $17.68 \mathrm{~mm}$ per event). In total, samples were collected from three $40 \mathrm{~L}$ dosing events and two $20 \mathrm{~L}$ dosing events for the current study.

To test the effect of extended antecedent dry weather conditions, columns were left to dry for periods of two, four and six weeks before the subsequent dosing to simulate three dry weather periods. As such, in this study, we refer to two periods: (1) 'wet weather periods', where the columns were dosed twice a week and dosing occurred at least once every two weeks; and (2) 'dry weather periods', where dosing did not occur for 2 weeks or more. The total of five events sampled for the current study comprised of four wet weather period sampling events and one four-week dry weather period sampling event.

\subsubsection{Inflow and Outflow Water Quality Sampling}

The inflow was analysed for E. coli concentration in every dosing event. One inflow sub-sample was collected from each 3-5 L pass and each sub-sample was analysed for E. coli using the Colilert 
method $^{\mathrm{TM}}$ [25]. Since the variations between each sub-sample were minimal within a single sampling day, only the geometric mean inflow E. coli concentrations are reported for each day. On days where laboratory-seeded microbial cultures were added to the inflow (i.e., in week 14, 26, 27, 31 and 41; Figure 1), volume-weighted composites were made from sub-samples taken from the inflow. These volume-weighted composites of the inflow were analyzed for the indicator microorganisms and pathogens of interest at NATA accredited laboratories using standard methods (FRNA coliphages: US EPA 1602, APHA 9224 and ISO 10705-1; C. perfringens: AS/NZS 4276.17.1:2000; Campylobacter spp.: an 11 tube MPN procedure and the AS 4276.19:2001; adenoviruses: cell culture technique followed by confirmation with polymerase chain reaction (PCR) [26]; Cryptosporidium: USEPA 1623 method with some modifications; refer to Table S1 in Supplementary Materials for further details on each microbial assay). On the same days, these volume-weighted inflow composites were also analysed for total suspended solids, total nitrogen, total phosphorus and heavy metal concentrations at NATA accredited laboratories using standard methods ([27,28] and ICP-MS for metals).

On the five sampling days (Figure 1), we collected into two composite samples from the total outflow drained from each column. The first composite outflow sample represented 'old' water (i.e., water which remained in the $\mathrm{SZ}$ and media pores from a prior event) and the second composite sample represented the 'new' water (i.e., water which was freshly filtered during the sampling day). The initial tracer study (See Supplementary Materials Figure S1 for more details on tracer test) demonstrated that during wet weather periods, approximately the first $10 \mathrm{~L}$ of outflow was old water and the remaining volume was the new water. Both old and new water samples were analysed for E. coli concentrations. Weights of all old and new water drained from each column were recorded, and these data were then used to derive a volume-weighted, event mean outflow E. coli concentration. Due to resource limitations, it was not possible to analyse old and new water separately for the other target faecal microorganisms. For the other target faecal microorganisms, the old and new water samples were combined (after separate aliquots were taken from the new and old water samples for E. coli analysis). A sub-sample taken from this composite sample was analysed for the reference pathogens and/or the other indicator microorganisms.

\subsubsection{Infiltration Rate Measurements}

Infiltration rates were measured on all five outflow sampling days (Figure 1) using a method similar to a previous study [29]. The ponding water level was recorded at regular intervals (3 min and $45 \mathrm{~s})$ for approximately one hour. The first ponding measurements were taken after all the stormwater had been applied to the systems, to ensure that the columns were saturated to a level similar to that of biofilters in the field. It should be noted that the infiltration rate obtained using this method does not represent the saturated hydraulic conductivity of the system (as the system is not necessarily saturated when the infiltration rates are measured), but rather what would be seen typically under field conditions, and is dependent on soil moisture prior to the measurements. The recorded ponding depths over the hour were plotted against time, and the gradient of this graph was taken as the average infiltration rate through the column.

\subsection{Data Analysis}

Microbial concentrations below the lowest detection limit were taken as the lowest detection limit, and the microbial concentrations above the highest detection limit were taken as the highest detection limit for analysis. Removal performance in terms of log reduction is the difference between the logarithmic (base 10) inflow concentration and the logarithmic outflow concentration. Log reduction data were found to be normally distributed according to the Shapiro-Wilk test. Therefore, the independent sample $t$-tests with the significance level, $\alpha$ taken as 0.05 was used to test the effect of biofilter vegetation (LC vs. WS) on the removal of the three indicator microorganisms and differences in indicator microorganism log removal rates. 


\section{Results and Discussion}

\subsection{Overall Removal Performance of Indicators and Reference Pathogens}

Contrary to other studies $[13,14]$, there was no notable differences in indicator concentration reductions between vegetated and un-vegetated controls ( $p>0.05$; independent samples $t$-test; Figure 2). Plants have previously been highlighted as a key covariant controlling faecal indicator removal due to advanced adsorption to roots and interactions with exudates and the rhizosphere; as such, our results might instead be reflecting the relatively higher importance of other design (e.g., presense of an SZ) and operational conditions (large vs. small inflow volumes). Nonetheless, the average E. coli log reduction of 1.2 is comparable to E. coli log reductions (1.2-1.4) observed in the authors' previous work in field conditions [30]. C. perfringens were removed better than E. coli ( $>2$ average; $p<0.05$; independent samples $t$-test) owing to their larger size which promotes physical straining by the media [7]. The inconsistent FRNA coliphage removal (ranging from net leaching to over 3 log removal) for both WS and LC is caused by the large variance in inflow concentrations (Supplementary Materials Table S2), variable operational conditions (as discussed below) and also due to the potential interactions between coliform bacteria and phages that can occur within biofiltration systems [7].

All reference pathogen concentrations were reduced by the vegetated biofilters, which is a substantial finding considering no previous data was available on stormwater biofilter capacity to remove these pathogens and the sampling events were designed to test the biofilters during very challenging operational conditions. However, of the three reference pathogens tested, Campylobacter spp. had the most variable and the lowest average removal rates ( 0.7 average log reduction). These results are explained by the highly variable inflow concentrations (Supplementary Materials Table S2) and the uncertainties associated with the current Australian standard method of analysis of thermophilic Campylobacter [31]. It is encouraging to note that the average Campylobacter spp. log reduction observed in the current study is comparable to the average Campylobacter spp. log reduction observed in the authors' previous work in field biofiltration systems [30]. Cryptosporidium oocysts were the most effectively removed reference pathogen by stormwater biofilters (1.7 average log reduction); as for C. perfringens, this is likely due also to its larger size [32]. Adenoviruses were removed, on average, but with a 1 log reduction. This reflects its smaller particle size, which prohibits active straining.

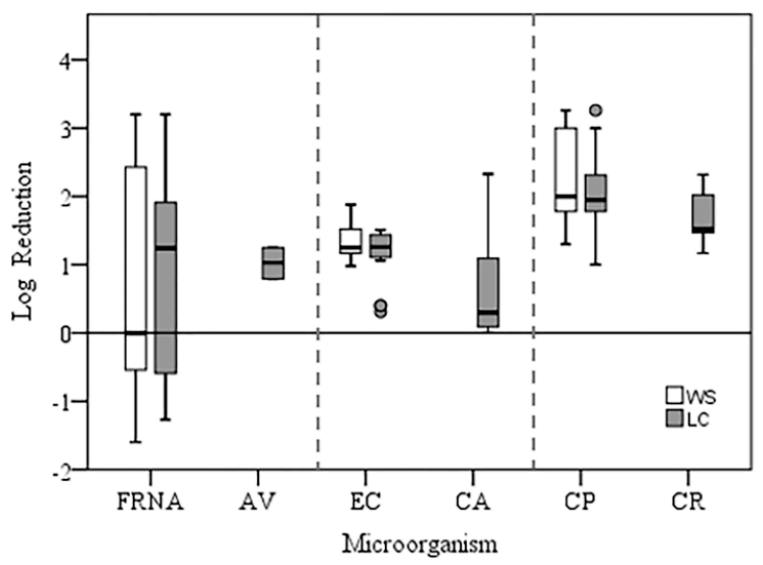

Figure 2. Overall reference pathogen and other indicator microorganism log reduction in LC and WS configurations. WS columns were not tested for any reference pathogens. Box plots for WS represent three sampling events (in week 14, 26 and 41) and the box plots for LC represent five sampling events (in week 14, 26, 27, 31 and 41). Microbial abbreviations: FRNA: FRNA coliphages; AV = adenovirus; $\mathrm{EC}=$ E. coli $\mathrm{CA}=$ Campylobacter $; \mathrm{CP}=$ Clostridium perfringens $; \mathrm{CR}=$ Cryptosporidium oocysts. 


\subsection{Effect of Dry Weather Periods}

Log reductions before and after four weeks of dry weather are shown in Figure 3a. E. coli log reduction performance decreased drastically after the 4-week dry period (median log reduction from 1.41 to 0.23$)$. Generally, $\mathrm{SZ}$ water is lost during extended dry weather periods due to evapotranspiration (Figure $3 \mathrm{c}$ shows a $50 \%$ reduction in outflow volume after the dry period even though the inflow volume in the preceding event was the same). This loss of SZ water diminishes the contribution of the 'old' SZ water to the effluent, which generally has lower E. coli concentrations because of its longer contact time and hence more microbial die-off [13]. As a result, the outflow after four weeks of drying is mainly comprised of freshly treated stormwater, which has relatively higher E. coli concentrations because of its shorter contact time. An increase in infiltration rates was also observed after four weeks of dry weather (Figure 3d), possibly due to the creation of cracks and macropores in the filter media. It is well known that increased infiltration rates lead to decreased bacterial adsorption to filter media/biofilms [33]. Therefore, it is evident that the combined effect of increased infiltration rates and decreased SZ water volume has led to a lower $E$. coli log reduction after the four weeks dry weather period.

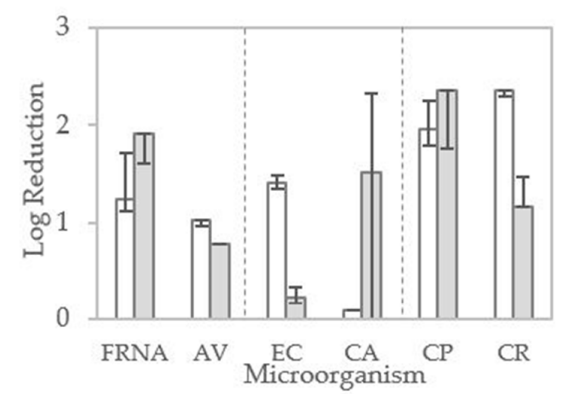

(a)

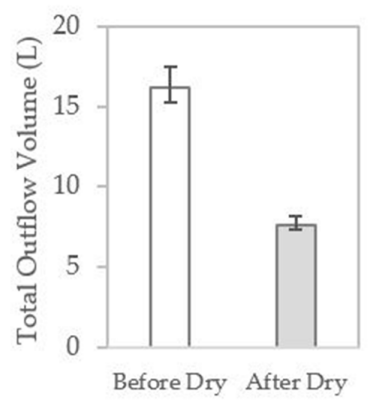

(c)

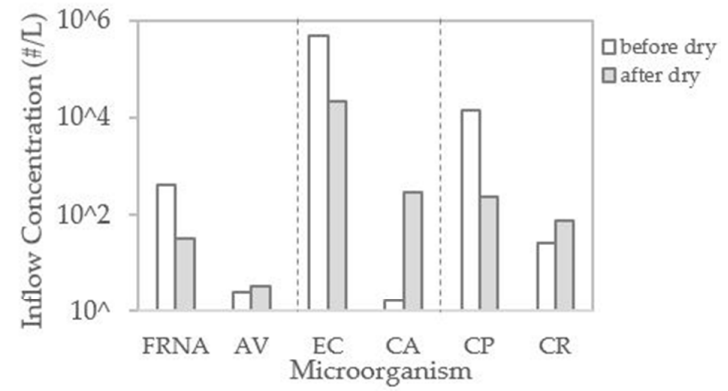

(b)

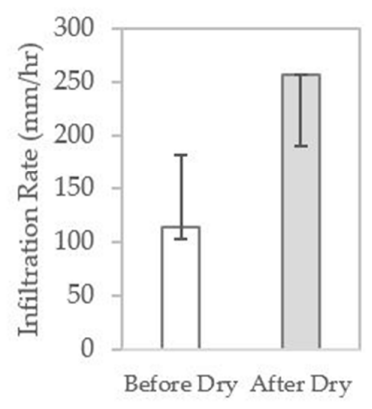

(d)

Figure 3. Change in log reduction (a), inflow concentration (b), total outflow volume (c) and infiltration rate (d) before and after the four-week dry period (in weeks 27 and 31) in LC columns; Bars represent the median value while error bars represent the minimum and maximum measured or estimated values. Unshaded bars represent sampling event on week 27, and shaded bars represent sampling event on week 31. Microbial abbreviations: FRNA: FRNA coliphages; AV = adenovirus; $\mathrm{EC}=$ E. coli $; \mathrm{CA}=$ Campylobacter $; \mathrm{CP}=$ Clostridium perfringens $; \mathrm{CR}=$ Cryptosporidium oocysts . (Cryptosporidium oocysts concentrations were below detection in all three outflow samples before the four-week dry period, and hence outflow concentration was taken as the limit of reporting, which was 1 oocyst/7 L). 
The other two indicator microorganisms showed different responses to the 4-week dry weather period. The $\log$ reduction of $C$. perfringens was relatively unaffected by the 4 -week dry period. One plausible explanation could be that despite the creation of some cracks and macropores, C. perfringens might have been retained by straining due to its large size [7]. Median log reductions in the virus indicator, FRNA coliphage, increased from 1.24 to 1.91 after the four-week dry period. Similar observations were reported in [7] in a previous laboratory experiment. One plausible explanation for this increased FRNA coliphage removal might be the increased FRNA coliphage inactivation under unsaturated conditions [34] prevailed in the column with almost all of the SZ water lost during the 4-week dry weather period (Nearly $9 \mathrm{~L}$ decrease in outflow volume after a 4-week dry period in Figure 3c).

Dry weather seemed to improve the removal of Campylobacter spp.( Figure 3a), but more plausibly the removal rates are instead explained by the differences observed in Campylobacter spp. inflow concentrations before and after the dry weather period (Figure 3b) [35]. Cryptosporidium oocyst removal rates decreased by $1.2 \mathrm{log}$ after the dry period. This could imply that oocysts retained from previous events are flushed out of the biofilters after dry weather periods due to cracks and macropores; importantly, even if these persistent oocysts have died during the dry period, the enumeration method employed here is still likely to detect them [36,37]. This effect was not observed for C. perfringens because their enumeration is culture based and hence will not detect dead organisms. Adenoviruses were largely unaffected by the dry weather period, reflecting the irrelevance of cracks and macropores (because of the size of the microorganisms) and submerged zone interactions (because of their ability to persist and culture-based enumeration).

\subsection{Effect of Event Size}

Log reductions observed in two different event sizes (20 L vs. 40 L) are shown in Figure 4a. Only FRNA coliphage and Campylobacter log reductions seemed to be notably different during the two events, and these differences in removal rates were most likely due to differences in inflow concentrations rather than the event size. Similarly, significantly different inflow adenovirus concentrations in the two events make it difficult to distinguish the effect of event size on adenovirus removal. On the other hand, inflow concentrations of Cryptosporidium oocysts and C. perfringens were comparable in both events, and overall removal rates were relatively unaffected by the event volume. One possible explanation for the relatively consistent removal of these two larger microorganisms is that most of these microbes were retained by straining, which was not affected by the event volume. On the other hand, other microbes such as FRNA coliphages are removed by adsorption and desorption, which are two removal process that can be affected by variation in event volume [18]. The relatively consistent E. coli log reductions observed during both events conflicts with the trend of decreasing E. coli log reduction with increasing event volume as reported in the authors' previous work [19]. A further investigation into E. coli inflow and outflow concentration revealed that the $E$. coli concentrations were different in the inflows of the two events, and it is likely that this masked any influence of the increased volume in the $40 \mathrm{~L}$ event. Hence, more testing with consistent inflow microbial concentrations is required to fully understand how removal is affected by different event volumes. 


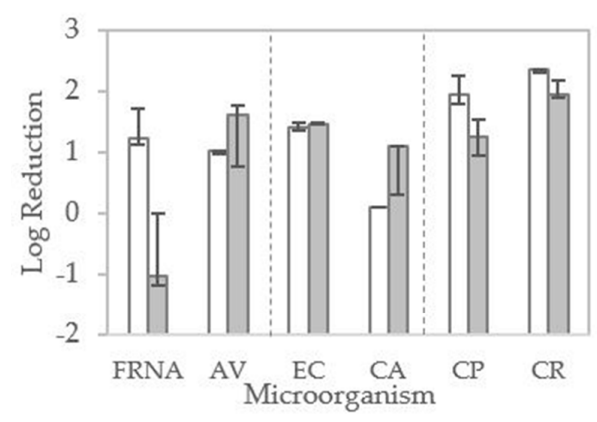

(a)

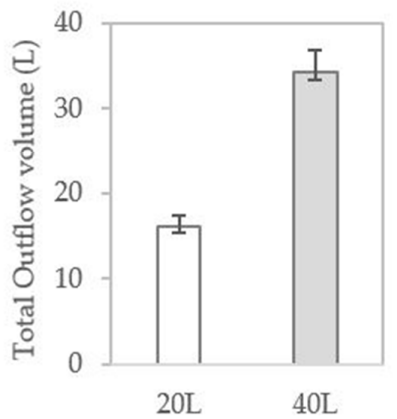

(c)

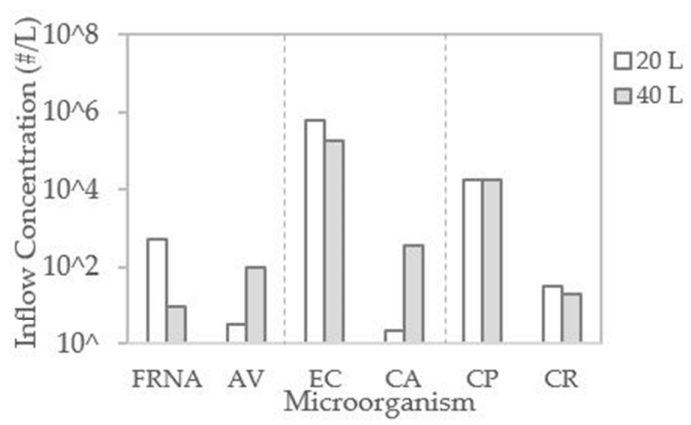

(b)

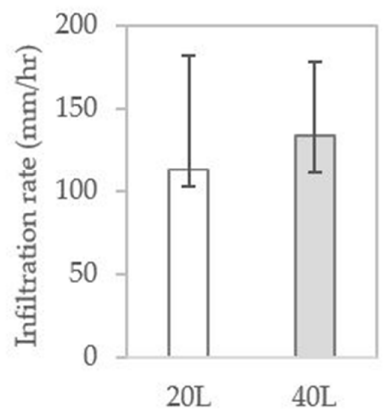

(d)

Figure 4. Change in log reduction (a), inflow concentration (b), total outflow volume (c) and infiltration rate (d) during a $20 \mathrm{~L}$ (in week 27) and a $40 \mathrm{~L}$ (in week 41) event in LC columns; Bars represent the median value while error bars represent the minimum and maximum measured or estimated values. Unshaded bars represent $20 \mathrm{~L}$ sampling event on week 27, and shaded bars represent $40 \mathrm{~L}$ sampling event on week 41. Microbial abbreviations: FRNA: FRNA coliphages; AV = adenovirus; $\mathrm{EC}=$ E. coli; $\mathrm{CA}=$ Campylobacter $; \mathrm{CP}=$ Clostridium perfringens $; \mathrm{CR}=$ Cryptosporidium oocysts.

\subsection{Comparison of Indicator and Reference Pathogen Removal}

Comparing the removal performances of the selected indicator microorganisms and reference pathogens revealed that indicator removal rates fail to consistently represent the removal rates of their corresponding reference pathogens. For instance, the average Campylobacter spp. log reduction rate was lower than that of E. coli (Figure 2). Furthermore, E. coli log reduction decreased after a long dry period while Campylobacter spp. log reduction rate showed an increase (Figure 3a). Similarly, the two microorganisms were affected differently by the event size (Figure 4a) with an increased Campylobacter spp. log reduction with an increased event volume while E. coli log reduction remained unaffected. However, conflicting trends between the two microorganisms may be due to large variances in inflow Campylobacter spp. concentrations.

The average Cryptosporidium oocysts log reduction was similar to that of $C$. perfringens. However, the impact of dry weather on these two microorganisms was different. Cryptosporidium oocysts $\log$ reduction decreased after a dry weather period while $C$. perfringens were relatively unaffected. This variation could be due to differences in enumeration methods (culture vs. microscopic). However, both microbes were relatively unaffected by the event volume.

Lastly, the average adenovirus log reduction was similar to that of FRNA coliphages, but adenoviruses were relatively unaffected by dry weather periods while FRNA coliphages showed an increased log reduction after a dry weather period. These conflicting responses to dry weather periods could be due to the differences in major removal mechanisms (attachment and die-off) and enumeration techniques. Likewise, both viruses showed opposite responses when the event volume was changed, but those responses were most likely due to the variances in inflow concentrations. 
These results reinforce the inadequacy of using just a single indicator microorganism to test the capacity of stormwater biofilters and as such, encourages the use of a suite of indicators and reference pathogens. Although more data is required to fully understand reference pathogen behaviour, this is one of the few sets of reference pathogen data in the context of stormwater biofilters. These data provide useful insight into the ability of biofilters in reducing actual pathogen concentrations rather than just indicator microorganisms. Further investigations could broaden our knowledge on the governing removal mechanisms of different pathogen types and how these mechanisms are affected by different biofilter designs and operational conditions.

\section{Conclusions}

Two main objectives of this investigation were to test the capacity of biofilters to remove pathogens and to compare the influence of design characteristics and operational conditions on the removal of faecal indicator microorganisms and reference pathogens. The laboratory-scale column study showed that stormwater biofilters are able to remove reference pathogens (Campylobacter spp., adenoviruses and Cryptosporidium oocysts) and the faecal indicator microorganisms, E. coli and C. perfringens. Out of the three tested common indicators, only $C$. perfringens and FRNA coliphages showed comparable overall log reductions with their corresponding reference pathogens, but then these indicators and their corresponding reference pathogens showed different responses when the stormwater biofilters were subjected to different operational conditions such as varying antecedent dry weather periods and different event volumes. This highlights that the removal processes of pathogens in stormwater biofilters cannot be accurately characterised by the behaviour of their corresponding indicator microorganisms under all operational conditions. An understanding of the key removal processes of individual microorganisms is critical when optimising stormwater biofiltration systems for reducing microorganism levels in stormwater. As such, this study demonstrates that more data on pathogen removal in stormwater biofilters must be collected, and the effects of different design characteristics and operational conditions should be tested.

Supplementary Materials: The following are available online at www.mdpi.com/2073-4441/9/12/949/s1, Figure S1: Change of outflow $\mathrm{KCl}$ concentration (normalised to the inflow concentration) with cumulative outflow during the tracer test trail in three replicates of WS un-vegetated columns, Table S1: Microbial assay description, Table S2: A summary of inflow and outflow microbial concentrations of each sampling round.

Acknowledgments: Authors wish to acknowledge Monash Water for Liveability and CRC for Water Sensitive Cities for financially contributing to this study and the Australian Research Council-Discovery Early Career Researcher Award (grant number DE140100524) for the financial support during the manuscript preparation. Authors also received funds from CRC for Water Sensitive Cities for covering the costs to publish in open access. Support from Yali Li, Minna Tom, Anthony Brosinsky, Christelle Schang, Peter Kolotelo, Kun Kim, Ashley Connelly and Ben Evans during the experimental duration is also gratefully acknowledged.

Author Contributions: Gayani Chandrasena, David McCarthy and Ana Deletic conceived and designed the experiments; Gayani Chandrasena and Rebekah Henry performed the experiments; Gayani Chandrasena and Anna Lintern analysed the data; Rebekah Henry contributed reagents/materials/analysis tools; Gayani Chandrasena wrote the paper; David McCarthy, Anna Lintern, Ana Deletic and Rebekah Henry reviewed the paper.

Conflicts of Interest: The authors declare no conflict of interest. The founding sponsors had no role in the design of the study; in the collection, analysis, or interpretation of data; in the writing of the manuscript, and in the decision to publish the results.

\section{References}

1. Mitchell, V.G.; Deletic, A.; Fletcher, T.D.; Hatt, B.E.; McCarthy, D.T. Achieving multiple benefits from stormwater harvesting. Water Sci. Technol. 2007, 55, 135-144. [CrossRef] [PubMed]

2. Urban Water Resources Research Council. Pathogens in Urban Stormwater Systems; American Society of Civil Engineers: Reston, VA, USA, 2014. 
3. National Health and Medical Research Council (NHMRC). Australian Guidelines for Water Recycling (Phase 2): Stormwater Harvesting and Reuse; Natural Resource Management Ministerial Council; Environment Protection and Heritage Council; National Health and Medical Research Council: Canberra, Australia, 2009.

4. Davis, A.P.; Shokouhian, M.; Sharma, H.; Minami, C. Water quality improvement through bioretention media: Nitrogen and phosphorus removal. Water Environ. Res. 2006, 78, 284-293. [CrossRef] [PubMed]

5. Facility for Advancing Water Biofiltration (FAWB). Adoption Guidelines for Stormwater Biofiltration Systems; Facility for Advancing Water Biofiltration, Monash University: Clayton, VIC, Australia, 2009; ISBN 978-0-9805831-1-3.

6. Hathaway, J.; Hunt, W.; Graves, A.; Wright, J. Field Evaluation of Bioretention Indicator Bacteria Sequestration in Wilmington, North Carolina. J. Environ. Eng. 2011, 137, 1103-1113. [CrossRef]

7. Li, Y.L.; Deletic, A.; Alcazar, L.; Bratieres, K.; Fletcher, T.D.; McCarthy, D.T. Removal of Clostridium perfringens, Escherichia coli and F-RNA coliphages by stormwater biofilters. Ecol. Eng. 2012, 49, 137-145. [CrossRef]

8. Mohanty, S.K.; Torkelson, A.A.; Dodd, H.; Nelson, K.L.; Boehm, A.B. Engineering Solutions to Improve the Removal of Fecal Indicator Bacteria by Bioinfiltration Systems during Intermittent Flow of Stormwater. Environ. Sci. Technol. 2013, 47, 10791-10798. [CrossRef] [PubMed]

9. Morales, I.; Atoyan, J.; Amador, J.; Boving, T. Transport of Pathogen Surrogates in Soil Treatment Units: Numerical Modeling. Water 2014, 6, 818-838. [CrossRef]

10. Schifman, L.; Kasaraneni, V.; Sullivan, R.; Oyanedel-Craver, V.; Boving, T. Bacteria Removal from Stormwater Runoff Using Tree Filters: A Comparison of a Conventional and an Innovative System. Water 2016, 8, 76. [CrossRef]

11. Horan, N.J. Faecal indicator organisms. In The Handbook of Water and Wastewater Microbiology; Mara, D., Horan, N.J., Eds.; Academic Press: San Diego, CA, USA; London, UK, 2003; ISBN 978-0-12-470100-7.

12. Rippy, M.A. Meeting the criteria: Linking biofilter design to fecal indicator bacteria removal: Linking biofilter design to FIB removal. Wiley Interdiscip. Rev. Water 2015, 2, 577-592. [CrossRef]

13. Chandrasena, G.I.; Pham, T.; Payne, E.G.; Deletic, A.; McCarthy, D.T. E. coli removal in laboratory scale stormwater biofilters: Influence of vegetation and submerged zone. J. Hydrol. 2014, 519, 814-822. [CrossRef]

14. Li, Y.; McCarthy, D.T.; Deletic, A. Escherichia coli removal in copper-zeolite-integrated stormwater biofilters: Effect of vegetation, operational time, intermittent drying weather. Ecol. Eng. 2016, 90, 234-243. [CrossRef]

15. Schifman, L.A.; Kasaraneni, V.K.; Sullivan, R.K.; Oyanedel-Craver, V.; Boving, T.B. New Antimicrobially Amended Media for Improved Nonpoint Source Bacterial Pollution Treatment. Environ. Sci. Technol. 2015, 49, 14383-14391. [CrossRef] [PubMed]

16. Kasaraneni, V.K.; Schifman, L.A.; Boving, T.B.; Oyanedel-Craver, V. Enhancement of Surface Runoff Quality Using Modified Sorbents. ACS Sustain. Chem. Eng. 2014, 2, 1609-1615. [CrossRef]

17. Mohanty, S.K.; Cantrell, K.B.; Nelson, K.L.; Boehm, A.B. Efficacy of biochar to remove Escherichia coli from stormwater under steady and intermittent flow. Water Res. 2014, 61, 288-296. [CrossRef] [PubMed]

18. Tong, M.; Li, X.; Brow, C.N.; Johnson, W.P. Detachment-Influenced Transport of an Adhesion-Deficient Bacterial Strain within Water-Reactive Porous Media. Environ. Sci. Technol. 2005, 39, 2500-2508. [CrossRef] [PubMed]

19. Chandrasena, G.I.; Deletic, A.; Lintern, A.; Henry, R.; McCarthy, D.T. Enhancing Escherichia coli removal in stormwater biofilters with a submerged zone: Balancing the impact of vegetation, filter media and extended dry weather periods. Urban Water J. 2017, submitted.

20. Bratieres, K.; Fletcher, T.; Deletic, A.; Somes, N.; Woodcock, T. Hydraulic and pollutant treatment performance of sand based biofilters 2010. In Proceedings of the 7th International Conference on Sustainable Techniques and Strategies in Urban Water Management, Villeurbanne, France, 28 June-1 July 2010.

21. Bratieres, K.; Fletcher, T.D.; Deletic, A.; Zinger, Y. Nutrient and sediment removal by stormwater biofilters: A large-scale design optimisation study. Water Res. 2008, 42, 3930-3940. [CrossRef] [PubMed]

22. Duncan, H.P. Urban Stormwater Quality: A Statistical Overview; Cooperative Research Centre for Catchment Hydrology: Melbourne, Australia, 1999.

23. Taylor, G.D.; Fletcher, T.D.; Wong, T.H.F.; Breen, P.F.; Duncan, H.P. Nitrogen composition in urban runoff-Implications for stormwater management. Water Res. 2005, 39, 1982-1989. [CrossRef] [PubMed]

24. Chandrasena, G.I.; Deletic, A.; Ellerton, J.; McCarthy, D.T. Evaluating Escherichia coli removal performance in stormwater biofilters: A laboratory-scale study. Water Sci. Technol. 2012, 66, 1132-1138. [CrossRef] [PubMed]

25. IDEXX-Laboratories. IDEXX-Laboratories Colilert ${ }^{\circledR}$ Test Kit; IDEXX-Laboratories: Westbrook, ME, USA, 2007. 
26. Allard, A.; Girones, R.; Juto, P.; Wadell, G. Polymerase chain reaction for detection of adenoviruses in stool samples. J. Clin. Microbiol. 1990, 28, 2659-2667. [PubMed]

27. APHA (American Public Health Association); AWWA (American Water Works Association); WPCF (Water Pollution Control Federation). Standard Methods for the Examination of Water and Wastewater, 21st ed.; American Public Health Association; American Water Works Association; Water Pollution Control Federation: Washington, DC, USA, 2005.

28. Hsomi, M.; Sudo, R. Simultaneous determination of total nitrogen and total phosphorus in freshwater samples using persulphate digestion. Int. J. Environ. Stud. 1986, 27, 267-275. [CrossRef]

29. Pham, T.; Payne, E.G.; Fletcher, T.D.; Cook, P.L.; Deletic, A.; Hatt, B.E. The influence of vegetation in stormwater biofilters on infiltration and nitrogen removal: Preliminary findings. In Proceedings of the 7th International Conference on Water Sensitive Urban Design (WSUD 2012), Melbourne, Australia, 21-23 February 2012.

30. Chandrasena, G.I.; Deletic, A.; McCarthy, D.T. Biofiltration for stormwater harvesting: Comparison of Campylobacter spp. and Escherichia coli removal under normal and challenging operational conditions. J. Hydrol. 2016, 537, 248-259. [CrossRef]

31. Henry, R.; Schang, C.; Chandrasena, G.; Deletic, A.; Edmunds, M.; Jovanovic, D.; Kolotelo, P.; Williamson, R.; Schmidt, J.; McCarthy, D. Environmental monitoring of waterborne Campylobacter: Evaluation of the Australian Standard and a hybrid extraction-free MPN-PCR method. Front. Microbiol. 2015, 6. [CrossRef] [PubMed]

32. Bradford, S.A.; Bettahar, M. Straining, attachment, and detachment of Cryptosporidium oocysts in saturated porous media. J. Environ. Qual. 2005, 34, 469-478. [CrossRef] [PubMed]

33. Stevik, T.K.; Aa, K.; Ausland, G.; Hanssen, J.F. Retention and removal of pathogenic bacteria in wastewater percolating through porous media: A review. Water Res. 2004, 38, 1355-1367. [CrossRef] [PubMed]

34. Jin, Y.; Chu, Y.; Li, Y. Virus removal and transport in saturated and unsaturated sand columns. J. Contam. Hydrol. 2000, 43, 111-128. [CrossRef]

35. Strecker, E.; Quigley, M.; Urbonas, B.; Jones, J.; Clary, J. Determining Urban Storm Water BMP Effectiveness. J. Water Resour. Plan. Manag. 2001, 127, 144-149. [CrossRef]

36. Enriquez, C.; Alum, A.; Suarez-Rey, E.M.; Choi, C.Y.; Oron, G.; Gerba, C.P. Bacteriophages MS2 and PRD1 in turfgrass by subsurface drip irrigation. J. Environ. Eng. 2003, 129, 852-857. [CrossRef]

37. Medema, G.J.; Bahar, M.; Schets, F.M. Survival of Cryptosporidium parvum, Escherichia coli, faecal enterococci and Clostridium perfringens in river water: Influence of temperature and autochthonous microorganisms. Water Sci. Technol. 1997, 35, 249-252.

(C) 2017 by the authors. Licensee MDPI, Basel, Switzerland. This article is an open access article distributed under the terms and conditions of the Creative Commons Attribution (CC BY) license (http://creativecommons.org/licenses/by/4.0/). 